\title{
Possibilities of Using Three-Dimensional Optical Scanning in Complex Geometrical Inspection
}

\author{
Tomaz Brajlih ${ }^{1, *}$ - Tadej Tasic ${ }^{1}$ - Igor Drstvensek ${ }^{1}$ - Bogdan Valentan ${ }^{1}$ - Miodrag Hadzistevic ${ }^{2}$ - \\ Vojko Pogacar1 - Joze Balic ${ }^{1}-$ Bojan Acko ${ }^{1}$ \\ 1 University of Maribor, Faculty of Mechanical Engineering, Slovenia \\ 2University of Novi Sad, Faculty of Technical Sciences, Serbia
}

Non-contact optical three-dimensional measuring, scanning and digitising are increasingly present in quality assurance systems. Simple scanning procedures, high density of data acquired in a single scan, and the possibility of integrated reverse engineering and inspection, are all advantages of optical scanning compared to conventional measuring methods. Due to the three-dimensional acquisition of measuring data, an optical scanner is often considered to be an alternative possibility for coordinate measuring machines. However, the accuracy of the measured data acquired by optical scanning (even with a high-end system) is still far below the level achieved by high-level coordinate measuring machines. This paper examines the possibilities of using a three-dimensional scanner for workpiece inspection. The first part presents a special field of workpiece inspection in which, even with currently achievable accuracy, optical scanning is a viable solution for the inspection of manufactured parts. In addition, the achievable dimensional accuracy of an optical scanner is tested by scanning several gauge blocks. In conclusion, a head to head comparison with a coordinate measuring machine is made by scanning and verifying a sphere. (C)2011 Journal of Mechanical Engineering. All rights reserved.

Keywords: 3D optical scanning, uncertainty of measurement, geometry inspection, rapid manufacturing, reverse engineering, quality assurance

\section{INTRODUCTION}

A three-dimensional optical scanner acquires geometry data from an existing physical object. This data is used to construct a virtual three-dimensional model of the scanned object that can be used for various applications, such as reverse engineering, inspection and quality management, rapid prototyping, cultural heritage documentation and restoration.

The research presented in this paper was performed using a GOM ATOS ${ }^{\text {TM }}$ II threedimensional scanner, which is currently installed at the Faculty of Mechanical Engineering in Maribor (Fig. 1). The ATOS ${ }^{\mathrm{TM}}$ scanning system is based on the triangulation principle: The sensor unit projects different fringe patterns onto the scanned objects, which are then recorded by two cameras. Each single measurement generates up to 4 million data points. The scanner records only those points visible by both cameras in a single scan. In order to digitize a complete object, several individual measurements are required from different angles. Based on reference points (circular markers), which are attached directly on to the object or on the measuring plate or a fixture, ATOS transforms these individual measurements automatically into a common global coordinate system.

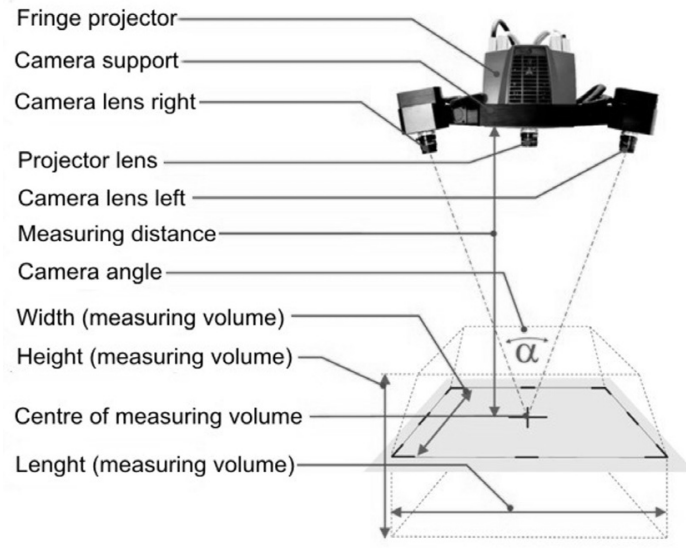

Fig. 1. Atos II optical scanner schematics

The ATOS ${ }^{\text {TM }}$ II three-dimensional scanner is equipped with several different projector and camera lenses setups (Table 1) that enable scanning to be performed inside different 
measuring volumes. The selection of larger measuring volume quickens the scanning of large parts by reducing the number of required consequent scans. However, the accuracy of scans decreases as volume envelope size increases.

Table 1. Measuring volume setups

\begin{tabular}{|c|c|c|c|}
\hline $\begin{array}{c}\text { Measuring } \\
\text { volume } \\
(L \times W \times H) \\
{[\mathrm{mm}]}\end{array}$ & $\begin{array}{c}\text { Mea- } \\
\text { suring } \\
\text { point } \\
\text { distance } \\
{[\mathrm{mm}]}\end{array}$ & $\begin{array}{c}\text { Projector } \\
\text { lens } \\
{[\mathrm{mm}]}\end{array}$ & $\begin{array}{c}\text { Camera } \\
\text { lens } \\
{[\mathrm{mm}]}\end{array}$ \\
\hline $1700 \times 1360 \times 1360$ & 1.33 & 6 & 8 \\
\hline $1200 \times 960 \times 960$ & 0.94 & 6 & 8 \\
\hline $800 \times 640 \times 640$ & 0.62 & 8 & 12 \\
\hline $550 \times 440 \times 400$ & 0.43 & 8 & 12 \\
\hline $350 \times 280 \times 280$ & 0.27 & 12 & 17 \\
\hline $250 \times 200 \times 200$ & 0.2 & 17 & 23 \\
\hline $175 \times 140 \times 135$ & 0.14 & 23 & 35 \\
\hline $135 \times 108 \times 95$ & 0.11 & 35 & 50 \\
\hline
\end{tabular}

\section{APPLICATIONS FOR 3D SCANNERS}

There are already several fields where three-dimensional scanning is an established method of data acquisition. In mechanical engineering, 3D scanners are often used for workpiece inspection, deformation analysis, reverse engineering and reengineering of moulds and dies and general quality control procedures [1]. Civil engineering also uses three-dimensional scanning during building inspection, custom fit furniture design, and cultural heritage protection and renovations. Forensics use optical scanning during crime scene investigation and data preservation. The textile industry uses scanning for digitalization of the human figure in custom fit product design. The movie industry also widely uses three-dimensional scanning for various CGI effects creation. Its use has also spread to marketing and advertisement industry [2]. This has already caused some degree of specialization by scanner manufactures regarding the indented field of use.

Our 3D scanner GOM ATOS ${ }^{\mathrm{TM}}$ II has already been used for many industrial measurement tasks, but recently we have strengthened co-operation with the University
Clinical Centre of Maribor, and one of our joint projects included measurement of cranial implants. This measurement will be presented in the next chapter.

\section{INSPECTION OF CRANIAL IMPLANTS}

The recent development of various rapid manufacturing technologies has opened new possibilities of customized product manufacturing. Lower accuracy, rough surfaces and relatively high production costs are still factors limiting the implementation of these technologies in the production processes. However, there are some special fields where rapid manufacturing is currently replacing conventional machining [3].

One of these fields is the manufacturing of customized cranial implants. Low accuracy demands, desired rougher surfaces and individual part production make rapid manufacturing technologies a better choice when manufacturing cranial implants (Fig. 2) [4]. Because these parts are essentially medical products, some form of inspection must be performed prior to implantation, in order to establish any manufacturing inaccuracies and possible postprocessing deformities.

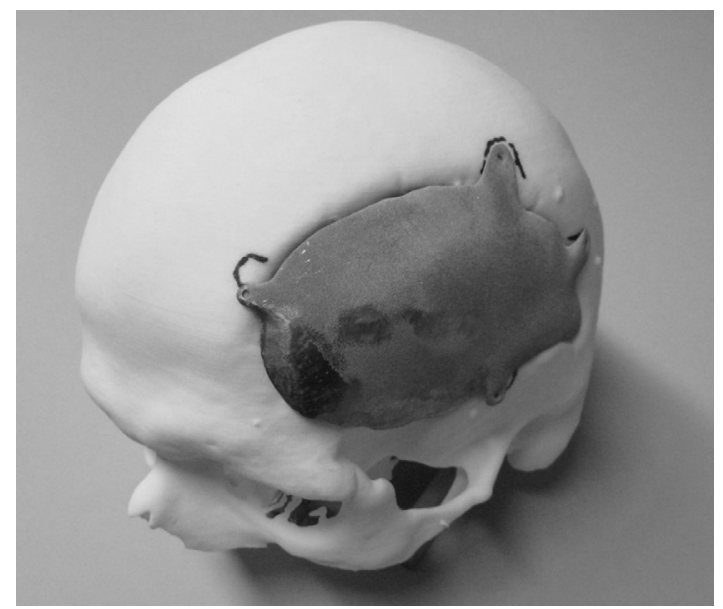

Fig. 2. Cranial implant and skull model

There are several factors that make three-dimensional optical scanning (Fig. 3) a favourable inspection method compared to a coordinate measuring machine. The CAD data of a cranial implant is usually (due to the established modelling method) a polygon mesh in the STL 
file format. This fact can make the accurate importation of CAD data (essential for inspection) into CMM software rather difficult. On the other hand, an STL mesh can be considered as a native format for three-dimensional scanner software, making inspection using STL CAD data much easier. In addition, accuracy demands regarding cranial implants are within the limits of $\pm 0.5 \mathrm{~mm}$, making the higher accuracy of a CMM (compared to a high-end optical scanner) unnecessary. There is also a possibility of measuring probe damage, especially in the case of continuous scanning due to implants usual (desired) surface roughness.

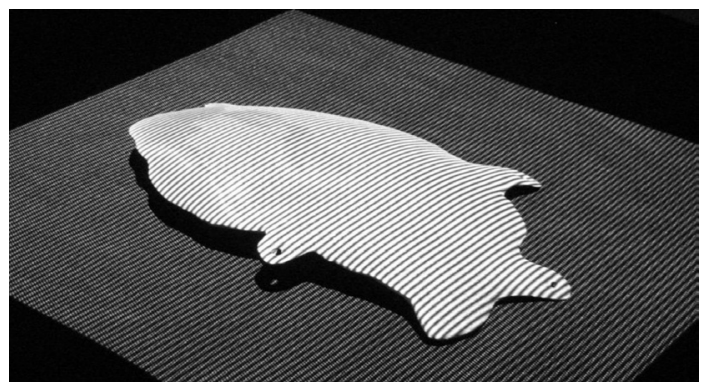

Fig. 3. Scanning of the implant

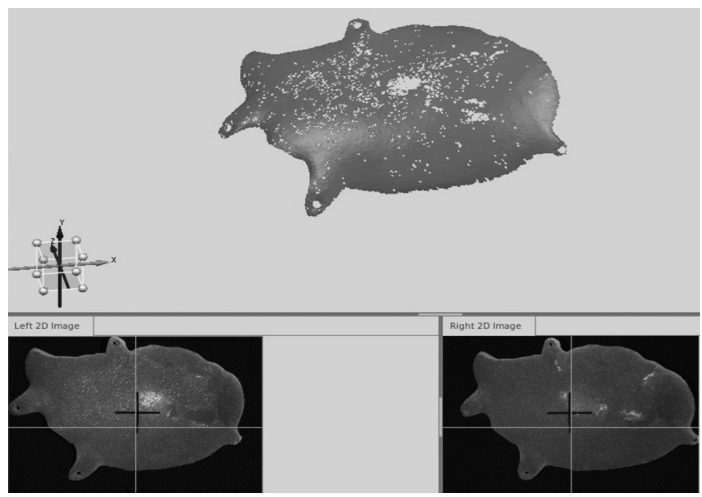

Fig. 4. The complete side of the implant was digitized in a single scan

The next section presents an established inspection method for a specific implant. This particular implant was manufactured using a selective laser melting method (on EOSINT M270 ${ }^{\mathrm{TM}}$ rapid manufacturing machine) from titanium alloy [5]. A physical model of the patient's skull was also manufactured (from polyamide) for rough inspection and engineersurgeon communication. However, an additional inspection prior to the operation was carried out by means of ATOS II optical scanner. This inspection was based on implants STL file incorporated during manufacturing. Two independent scans of each side of the implant were taken (Fig. 4). Each side was polygonized into an independent mesh.

An essential step during the part inspection is the mutual registration of scanned and CAD data. In ATOS software, registration is usually performed in two steps. Firstly, the meshes are manually registered by marking four (or more) common points on each mesh [6]. Due to two independent meshes being the results, both were registered separately (Fig. 5).

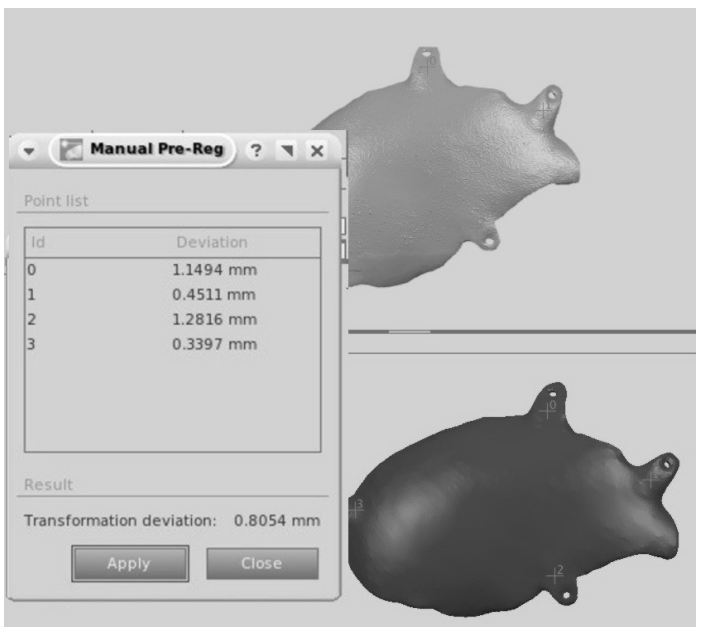

Fig. 5. Manual pre-registration of parts

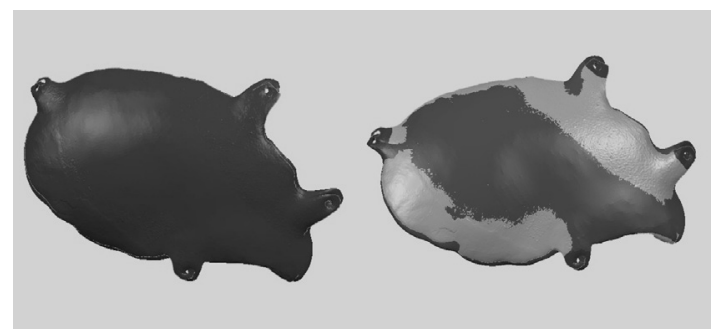

Fig. 6. Global vs. local registration

Semi-automatic best-fit registration is performed over the next step. Inspection of the implant was performed by best-fit registration using two different strategies. One strategy was by taking into account both meshes globally and the other by just regarding the local fixture structure (Fig. 6). This resulted in slightly different colourcoded deviation meshes. Both results are useful for the final verification of the manufactured implant, 
which is basically an engineer and surgeon mutual go/no-go decision prior to operational implantation.

By observing the inspection results (Fig. 7) we can note some problematic areas regarding the part (especially areas where a support structure had to be removed), where deviation is greater than desired $\pm 0.5 \mathrm{~mm}$ limits. However, due to these areas not being critically located, the implant was approved, and later successfully implanted.

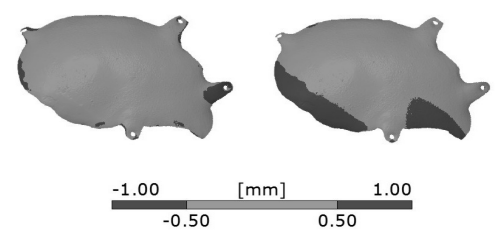

Fig. 7. Colour coded deviation mesh (global vs. local registration)

\section{EXPERIMENTAL UNCERTAINTY EVALUATION}

Due to complex calculations regarding 3D geometry from a very large number of measured points, it is almost impossible to calculate universal task-independent uncertainty in accordance with [7] and [8] for three-coordinate measuring machines. Calibration procedures for establishing the measuring uncertainty of CMMs are usually task-dependent and are used in special cases for very precise measuring tasks. However, the industry seeks universal CMM checks, which are fast and give sufficient information on the expected accuracy over a wide range of measuring tasks. Acceptance and reverification tests were standardized for this reason [9]. Different artefacts such as ball plates, step gauges, gauge blocks, rings and balls are used to verify uncertainty, as specified by the CMM producer. However, no such procedures have been generally accepted and standardized for 3D scanners and other optical devices. The producers of such devices have developed their own standards and perform periodical checks for their customers.

We have been attempting to transform our rich experiences in CMM verification in the field of 3D scanning. The first verifications were performed by means of scanning gauge blocks and balls. Further work is presently focused on developing special $3 \mathrm{D}$ artefacts and corresponding verification procedures. The work is being executed within the Euramet joint research project TP 3 JRP 2.2.

Our first verifications of the 3D scanner GOM ATOS II were limited to the smallest measuring volume in which the best accuracy is expected.

\subsection{Gauge Blocks Scanning}

Several gauge blocks were scanned and digitised in order to test the achievable accuracy of the optical scanner (Fig. 8). Scanning was performed using the smallest measuring volume in order to acquire as accurate scans as possible. Also, the number of subsequent scans was limited to two subsequent scans in order to minimize an error during scan assembly. Two scans were necessary to acquire enough data about both gauge block reference surfaces.

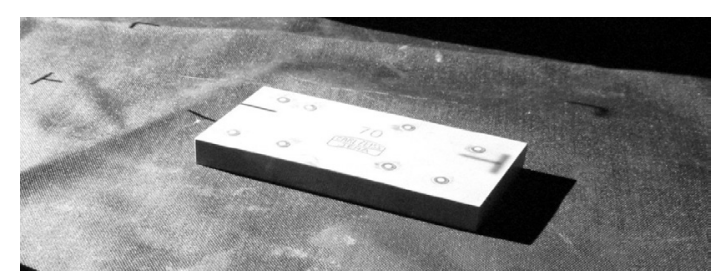

Fig. 8. Gauge block scanning

The digitizing and post-processing of the scanned data was performed using ATOS ${ }^{\mathrm{TM}}$ firmware. The first step was to take two subsequent scans of the gauge block (Fig. 9).

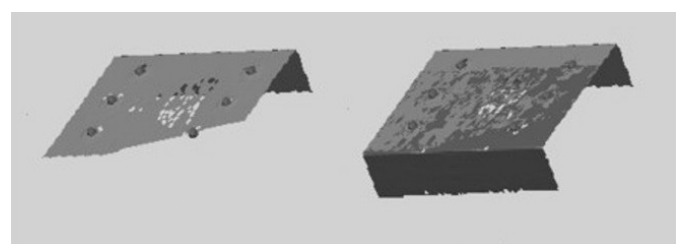

Fig. 9. Scan assembly

The initial result of scanning is a point cloud file of acquired points. This form is unsuitable for further work so the next step was to polygonize the point cloud into three-dimensional polygonal mesh. The polygonization process (Fig. 10) can be controlled using several parameters. For this test the reference point areas were cut-out, 
the polygonization detail was high, and we did not initially perform post processing.

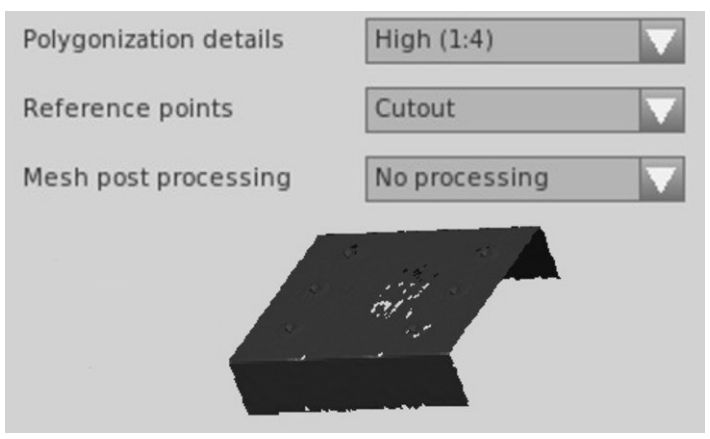

Fig. 10. Polygonization of point cloud

In the next step the undesirable data (unintentionally scanned parts of the measuring table) were removed. Also the scan noise was removed by smoothing the mesh using an allowed surface deviation of $0.005 \mathrm{~mm}$ (Fig. 11). Finally, the mesh was checked for possible triangulation errors (bad edges, reverse normals, etc.).

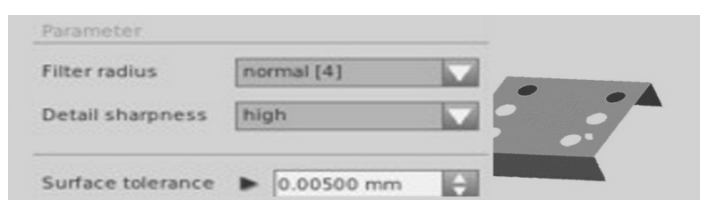

Fig. 11. Mesh postprocessing

Data about gauge block length was acquired by the following procedure. Firstly, a few triangles were selected on one of the reference plains. Then, the selection of triangles was increased by curvature in order to select as many triangles as possible describing the desired plane. A best-fit plane primitive was created based on this selection. All points inside the 3 -sigma limits of the selected triangles were taken for plane creation (Fig. 12).

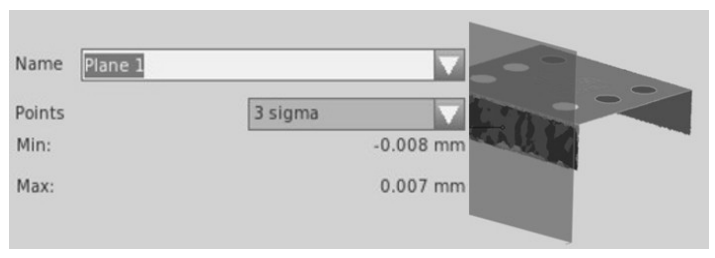

Fig. 12. Plane definition
Next, 9 points were selected on the opposite side of the gauge block in the following pattern. One approximately at the centre of the surface, four in the surrounding area, and four close to the corners (Fig. 13). Then, nine projected normal distances for these points to the plane 1 were measured.

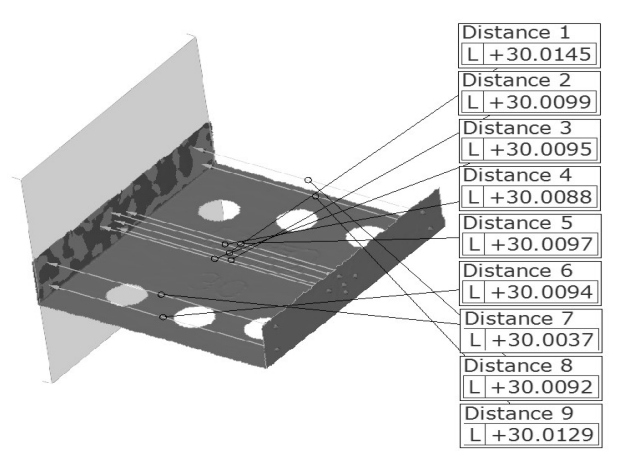

Fig. 13. Projected point-distance definition

An average for these nine distances was calculated as a result of the gauge block scanning. Three different gauge blocks were taken $(20,30$ and $70 \mathrm{~mm}$ nominal) for the purpose of this test. Each gauge block was scanned ten times.

The results of the gauge block scanning (Figs. 14 to 16):

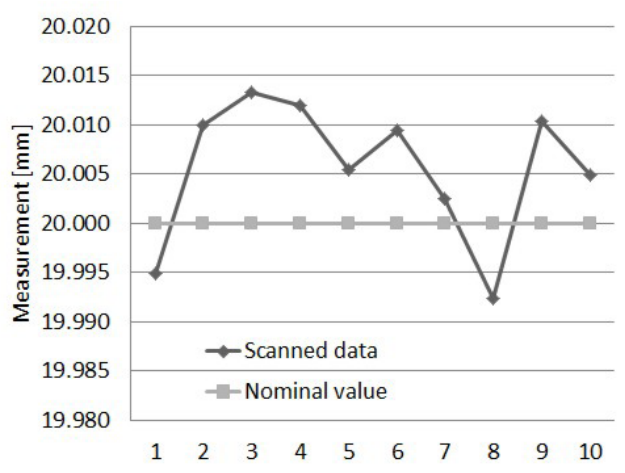

Fig. 14. Results of the $20 \mathrm{~mm}$ gauge block scanning

The above diagrams show scattering around nominal value within certain limits not systematically dependent on the scanned nominal length [7]. In fact, the scattering at $70 \mathrm{~mm}$ is somewhat higher than the other two, but the mean 
deviation from the nominal length is the smallest one. Standard deviations for different nominal lengths are $s_{20}=7.1 \mu \mathrm{m}, s_{30}=5.9 \mu \mathrm{m}, s_{70}=11.2$ $\mu \mathrm{m}$.

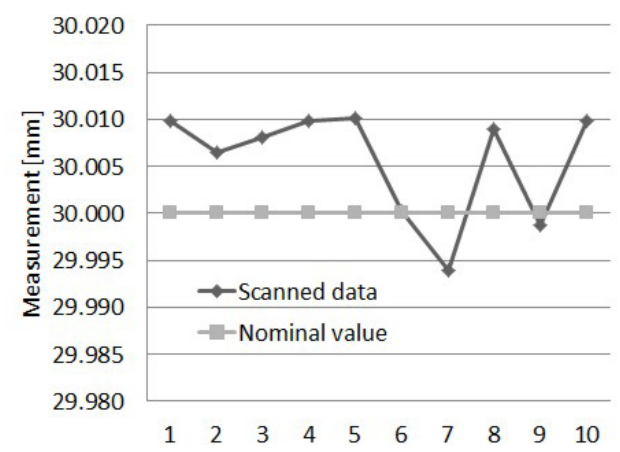

Fig. 15. Results of the $30 \mathrm{~mm}$ gauge block scanning

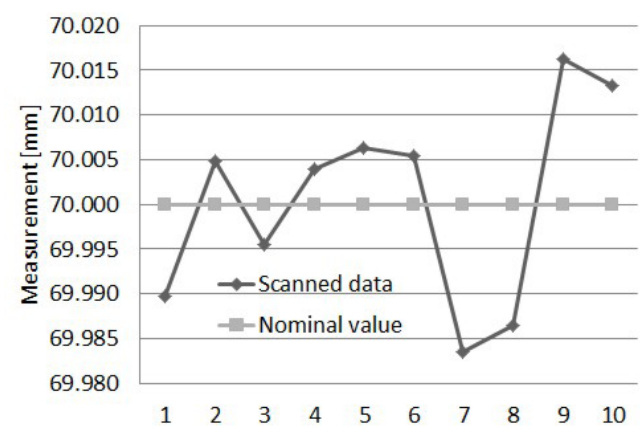

Fig. 16. Results of the $70 \mathrm{~mm}$ gange block scanning

While the deviations of the arithmetic means are as follows: $\bar{d}_{20}=7.1 \mu \mathrm{m}, \bar{d}_{30}=5.9 \mu \mathrm{m}$, $\bar{d}_{70}=11.2 \mu \mathrm{m}$.

Since the mathematical model of this measurement is very complex, it is assumed that the uncertainty results in scattering and systematic deviations [7] and [10]. The propagation law gives us the following relations:

$$
\begin{aligned}
& u_{20}=\sqrt{\bar{d}_{20}{ }^{2}+s_{20}^{2}}=9.0 \mu \mathrm{m}, \\
& u_{30}=\sqrt{\bar{d}_{30}^{2}+s_{30}^{2}}=8.1 \mu \mathrm{m}, \\
& u_{70}=\sqrt{\bar{d}_{70}^{2}+s_{70}^{2}}=11.2 \mu \mathrm{m} .
\end{aligned}
$$

The above uncertainties differ a little, but no systematic dependence on scanned length can be observed. Therefore, it is assumed that standard uncertainty is within the limits of $u=12$ $\mu \mathrm{m}$ over the whole measurement range. Expanded uncertainty at a confidence level of approx. $95 \%$ is then $U=25 \mu \mathrm{m}$.

\subsection{Issue of Spray Coating Scanned Parts}

Since optical scanners are based on optical data acquisition, there are problems when scanning parts with reflective or dark coloured surfaces. Often, it is necessary to coat the surface with a white spray in order to scan a certain part. In our case the gauge block surfaces were too reflective for scanning without applying a small amount of spray to the surface. The thickness of the spray coating inevitably contributes to error regarding scanned data. The manufacturer of the Ti-oxidebased spray usually used for these purpose claims that the thickness of the coating should be below $0.001 \mathrm{~mm}$ if the spray is used appropriately. The definition of appropriate spray use is highly subjective and described only as applying as little spray as (and when) necessary. This very much depends on experience and skill of the person performing the spraying (and scanning). In order to roughly examine the possible influence of spray coating, the $20 \mathrm{~mm}$ and $30 \mathrm{~mm}$ gauge blocks were (after the initial scanning) sprayed again and this time the coating was really exaggerated far beyond the "appropriate use" level. Both blocks were then scanned again (each twice) (Fig. 17).
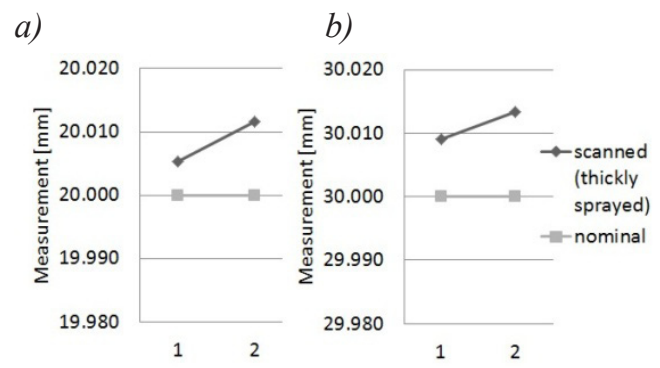

Fig. 17. Results of thickly sprayed gauge block scanning; a) $20 \mathrm{~mm}$ gauge block, b) $30 \mathrm{~mm}$ gauge block

Both results show scanning error well within the limits set by previous testing. It can be assumed, that among other parameters which also contribute to scanning inaccuracy (nominal resolution, scan assembly, polygonization and 
mesh smoothing, etc.); spray thickness does not have a predominant influence. Naturally, it cannot be disregarded, but at the same time the fact that some (a majority) of parts have to be sprayed does not automatically disqualify optical scanning as a future alternative to conventional inspection methods.

\subsection{Sphere Scanning}

The next phase of testing was performed by scanning a metal sphere. The first reason for this phase was a step towards a more complex geometry of the scanned part, which makes a three-dimensional scanner a more suitable means. Secondly, by scanning a sphere, necessary data for geometrical primitive creation can be acquired by a single scan, eliminating the error caused by subsequent scan assembly [11]. Additionally, verification of the scanned data was made by comparing the scanned results to the measured results gathered by the coordinate measuring machine.

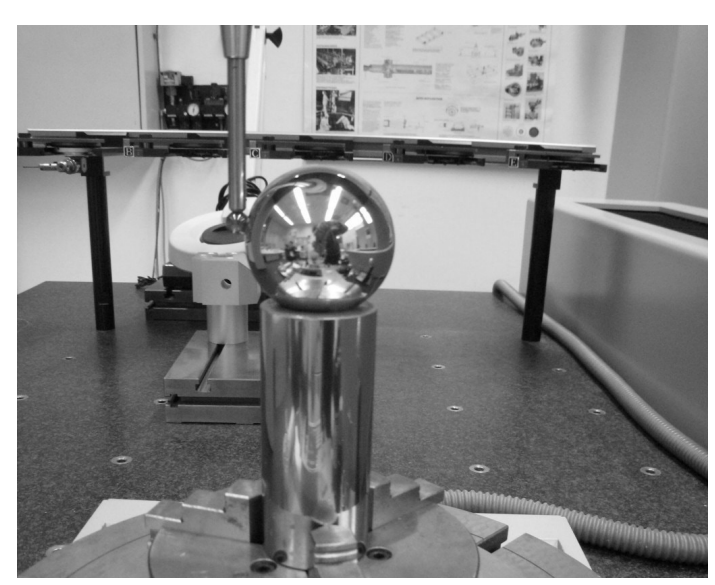

Fig. 18. Reference sphere measurement with a CMM ZEISS UMC 850

The sphere was measured using a Zeiss UMC- $850^{\mathrm{TM}}$ coordinate measuring machine (Figs. 18 and 19) by using standard procedure for sphere measurements [12]. Five subsequent measurements were taken. Then, the same ball was scanned (five times) by means of the ATOS ${ }^{\mathrm{TM}}$ II optical scanner (Fig. 20). Each scanning consisted of a single scan and subsequent sphere primitive generation based on the collected data [13].

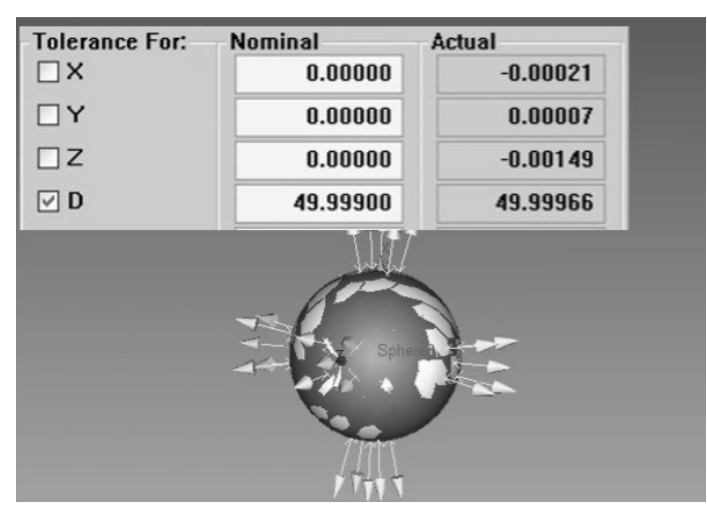

Fig. 19. CMM sphere inspection

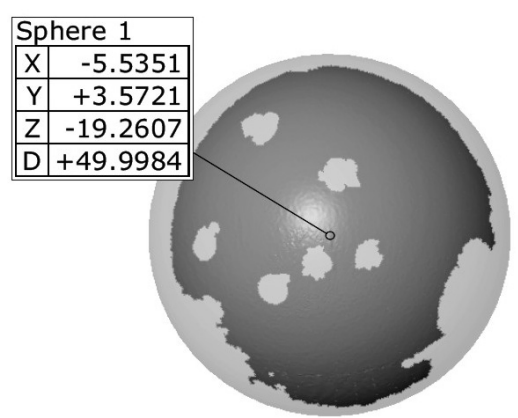

Fig. 20. Sphere primitive definition from scanned data

The diameters of the generated best-fit primitives were taken as a result of scanning. The following diagram compares the results of scanning with those acquired with the CMM (Fig. 21).

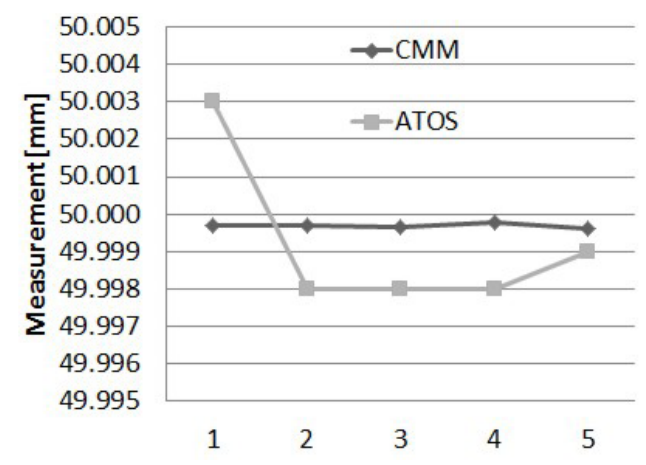

Fig. 21. Sphere verification ATOS vs. CMM

The results for the sphere are much closer to the CMM data than the results of gauge blocks compared to their nominal values. This increase 
in accuracy can be attributed to the elimination of subsequent scan assembly error, during the postprocessing of the scanned data. It has to be noted that it was also necessary for the sphere to spraycoat prior to scanning, due to a reflective surface.

If the uncertainty is estimated in the same simplified way as in the case of gauge block scanning, the expanded uncertainty at $k=2$ is $U=5 \mu \mathrm{m}$.

\section{CONCLUSION}

This paper is the result of research of the possibilities of customized medical implant inspection. Complex geometry, rough surface and polygon-only CAD data are all common properties of customized implants manufactured by additive technologies. This makes conventional coordinate measuring machines rather unsuitable for this type of inspection [14]. This resulted in a search for alternative methods, and optical scanning seemed a viable solution. Several tests on achievable accuracy were performed by means of scanning gauge blocks and other well-defined geometrical forms. These tests proved that by using a highend system, optical scanning can be successfully used in complex geometrical inspection and for currently defined accuracy demands for cranial implants. With the future development of optical scanning system and the increasing accuracy of scanned data, the use of this system will undoubtedly widen to other areas of inspection, as an alternative to conventional measurement methods.

\section{REFERENCES}

[1] GOM. Quality control of injection moulded parts, from http://www.gom.com/EN/B0C. html, accessed on: 2009-05-31.

[2] Pogacar, V. (2007). Integrated renaissance of design. Proceedings of the $1^{\text {st }}$ DAAAM International specialized conference on additive technologies, p. 9-12.

[3] Dolinsek, S. (2005). Wear characteristics of laser sintered molding tools. Wear - An International Journal on the Science and Technology of Friction, Lubrication and Wear, vol. 259, no. 7-12, p. 1241-1247.

[4] Drstvensek, I., Strojnik, T., Brajlih, T., Valentan, B. (2007). Rapid Technologies supporting surgical operation - case study. Proceedings of the $1^{\text {st }}$ DAAAM International specialized conference on additive technologies, p. 53-56.

[5] Drstvensek, I. (2004). Layered Technologies. Faculty of Mechanical Engineering, Maribor.

[6] Wesche, L. (2006) GOM ATOS II users guidelines. GOM, Braunschweig.

[7] BIPM. Evaluation of measurement dataGuide to the Expression of Uncertainty in Measurement from http://www.bipm. org/utils/common/documents/jcgm/ JCGM_100_2008_E.pdf, accesed on: 201003-10.

[8] Ačko, B. (2003). A universal model for evaluation measuring uncertainty in calibration. International Journal of Simulation Modelling, vol. 2, no. 4, p. 121129.

[9] EN ISO 10360 (2000). Geometrical product specifications (GPS) - Acceptance and reverification tests for coordinate measuring machines (CMM), parts 1-5. International Organization for Standardization. Geneva.

[10] Ačko, B., Godina, A. (2005). Verification of the conventional measuring uncertainty evaluation model with Monte Carlo simulation. International Journal of Simulation Modelling, vol. 4, no. 2, p. 76-84.

[11] Balič, J., Klančnik, S., Brezovnik, S. (2008). Feature extraction from CAD model for milling strategy prediction. Strojniški vestnik - Journal of Mechanical Engineering, vol. 54, no. 5, p. 301-307.

[12] Ačko, B. (2007). Calibration of measuring instruments on a coordinate measuring machine. Advances in Production Engineering \& Management, vol. 2, no. 3, p. 127-134.

[13] Yin, Z.W. (2004). Direct integration of reverse engineering and rapid prototyping based on the properties of NURBS or B-spline. Precision Engineering, vol. 28, no. 3, p. 293-301.

[14] Gusel, A., Ačko, B., Mudronja, V. (2009). Measurement uncertainty in calibration of measurement surface plates flatness. Strojniški vestnik - Journal of Mechanical Engineering, vol. 55, no. 5, p. 286-292. 